\title{
Non-Mucoid Pseudomonas aeruginosa
}

National Cancer Institute

\section{Source}

National Cancer Institute. Non-Mucoid Pseudomonas aeruginosa. NCI Thesaurus. Code C139103.

The wildtype form of Pseudomonas aerug inosa that does not produce an extracellular mucoid alginate. 